\title{
False-Positive Radioiodine Uptake in Simple Ovarian Cyst in a DTC Patient: A Case Report
}

\author{
Tao Wu, Xuefeng Zhao and Huiqin $\mathrm{Xu}{ }^{*}$ \\ Department of Nuclear Medicine, The First Affiliated Hospital of Anhui Medical University, Hefei, China
}

Abnormal radioildine uptake can be caused by various pelvic lesions in differentiated thyroid cancer patient. Here we presented an abnormal uptake in the left side of the pelvic cavity on postablative I-131 scintigraphy in a 51-year-old woman with history of stage T1aN1M0 papillary thyroid cancer. The SPECT/CT fused imaging revealed the lesion in the left ovary. Laparoscopic bilateral adnexectomy showed a left ovarian mass $(5 \mathrm{~cm})$ and pathologic finding showed a simple ovarian cyst. The nonstimulated Tg immediately decreased to $143 \mathrm{ng} / \mathrm{ml}$ after bilateral adnexectomy 3 days later and to $0.109 \mathrm{ng} / \mathrm{ml}$ after 4-month follow-up. Timely intervention measures are very necessary for patients with ovarian cyst with abnormally elevated Tg level.

OPEN ACCESS

Edited by:

Rosaria Maddalena Ruggeri,

University of Messina, Italy

Reviewed by:

Petra Petranović Ovčariček, University Hospital Center Sestre

Milosrdnice, Croatia

Alfredo Campenni',

University of Messina, Italy

${ }^{*}$ Correspondence:

Huiqin Xu

hfhuiqinxu@163.com

Specialty section: This article was submitted to Cancer Imaging and Image-directed Interventions,

a section of the journal

Frontiers in Oncology

Received: 07 February 2021 Accepted: 11 May 2021 Published: 31 May 2021

Citation:

Wu T, Zhao X and Xu H (2021) False-Positive Radioiodine Uptake in Simple Ovarian Cyst in a

DTC Patient: A Case Report.

Front. Oncol. 11:665135.

doi: 10.3389/fonc.2021.665135
Keywords: false-positive, radioiodine, simple ovarian cyst, thyroid cancer, single photon emission computed tomography/computed tomography

\section{INTRODUCTION}

Radioiodine (I-131) diagnostic whole body scan (WBS) is a very effective test in the treatment strategy of differentiated thyroid cancer (DTC). Single photon emission computed tomography (SPECT) is the most commonly used device to identify the residual thyroid and distant metastases. This is mainly due to the fact that most DTC cells can accumulate iodine through the action of the sodium-iodine symporter (NIS) (1). Despite its high sensitivity, its specificity is poor due to the lack of detailed anatomical localization in planar imaging (2). Because false-positive images often occur due to physiological ingestion, such as retention of radioiodine in the gastrointestinal tract, salivary gland uptake, and lesions in other parts of organs, such as mucinous cystadenoma (3), struma ovarii (4), endometrial cyst (5), gallbladder stones (6), hepatic cyst (7), renal cyst (8), nabothian cyst (9). SPECT combined with X-ray computed tomography (SPECT/CT) fusion imaging can provide additional information to distinguish between metastatic lesion and other abnormal uptake. Here we presented a clinical case with local pelvic abnormal uptake, where SPECT/CT accurately located the cystic lesion of left ovary which was pathologically confirmed to be a simple ovarian cyst.

\section{CASE PRESENTATION}

On March 5, 2018, a 51-year-old woman went to our hospital with the chief complaint of "right thyroid nodule" for subtotal thyroidectomy and central lymph node dissection. The preoperative serum thyroglobulin $(\mathrm{Tg})$ level was $118.28 \mathrm{ng} / \mathrm{ml}(3.5-77 \mathrm{ng} / \mathrm{ml})$. Postoperative pathology confirmed bilateral multifocal papillary thyroid carcinoma with a stage T1aN1M0 (four lesions about $0.2-0.6 \mathrm{~cm}$ in diameter, and one metastatic lymph node in the right central region, and no other metastatic lesions). Five months after surgery she underwent a radioiodine therapy as remnant ablation and adjuvant (10) with an activity of $3.7 \mathrm{GBq}(100 \mathrm{mCi})$ of I-131. The nonstimulated Tg level was 
9,572 ng/ml 1 month before radioiodine remnant ablation. After 18 days of thyroid hormone withdrawal, her serum $\mathrm{Tg}$ level was $11,488 \mathrm{ng} / \mathrm{ml}$ with antithyroglobulin antibodies (A-Tg) of $37.9 \mathrm{IU} / \mathrm{ml}$ (manufacturer cutoff level $<115 \mathrm{IU} / \mathrm{ml}$, limit of quantitation not available), and the thyroid-stimulating hormone (TSH) concentration was $7.91 \mathrm{mIU} / \mathrm{L}(0.27-4.20 \mathrm{mIU} / \mathrm{L})$. The post-treatment I-131-WBS (Figure 1A, anterior view; Figure 1B, posterior view) performed 3 days after I-131 administration revealed intense radioiodine uptake in thyroid bed in the neck and unexpected uptake in the left side of the pelvic cavity. Further SPECT/CT fused imaging was performed on the symbia T16 scanner (Siemens Medical Solutions) using a $128 \times 128$ matrix, 1 zoom, $30 \mathrm{~s}$ per frame and a CT scan layer thickness of $5 \mathrm{~mm}$ to distinguish the source of the pelvic unexpected uptake. The axial images (Figure 1C, SPECT; Figure 1D, CT; and Figure 1E, fusion) demonstrated the unexpected uptake corresponded to a cystic lowdensity lesion of approximately $3.2 \times 2.4 \mathrm{~cm}$ in the left adnexa region. The pelvic ultrasonography was then performed, which showed a $4.3 \times 4.0 \mathrm{~cm}$ liquid area with internal separation in the left adnexa region (Figure 1F). Two weeks later, laparoscopic bilateral adnexectomy was performed under general anesthesia and a 5-cm mass of the left adnexectomy was found intraoperatively. Finally pathologic finding showed a simple ovarian cyst (Figure 1G). Three days after surgery, the nonstimulated Tg level immediately decreased to $143 \mathrm{ng} / \mathrm{ml}$ from stimulated state (11488 ng/ml).

After a 4-month follow-up, the nonstimulated serum Tg level decreased from 143 to $0.109 \mathrm{ng} / \mathrm{ml}$. After 1 day of administration of $185 \mathrm{MBq}(5 \mathrm{mCi})$ of I-131, excepting for the physiological retention of stomach (black arrows) and bladder (red arrow), no radioactive uptake was observed in the neck and pelvic cavity on the diagnostic I-131-WBS (Figure 2). So further SPECT/CT fused imaging was not performed. Up to now, the patient was regularly reexamined for thyroid hormone and $\mathrm{Tg}$ level, as well as cervical ultrasound. No abnormal tissue and significant lymph node were observed on the cervical ultrasound images. The Tg level was stable between 0.1 and $0.5 \mathrm{ng} / \mathrm{ml}$ after twice L-T4 withdrawal.

\section{DISCUSSION}

Iodine is an essential constituent for the synthesis of thyroid hormones. The uptake of iodine by thyroid follicular cells mainly depends on the expression of NIS in the basolateral membrane. The radioactive isotopes (I-131) of iodine can be quickly absorbed, oxidized and organized by thyroid follicular cells with an effective half-life of 7.3 days due to its similar physical and chemical properties. Based on this principle, radioiodine has been widely used in the diagnosis and treatment of differentiated thyroid cancer.

NIS also slightly expressed in the epithelial cells of other normal tissues, such as salivary glands, lacrimal glands, choroid, gastric mucosa and lactation mammary gland (11). False-positive lesions often appear on I-131-WBS images. In addition, the causes of false positives mainly include physiological retention, contamination of physiological secretions and some non-thyroid related benign and malignant lesions. For instance, biliary duct dilatation can also lead to local hepatic uptake and the metabolism of radioiodinated thyroid hormones can cause diffused hepatic uptake.

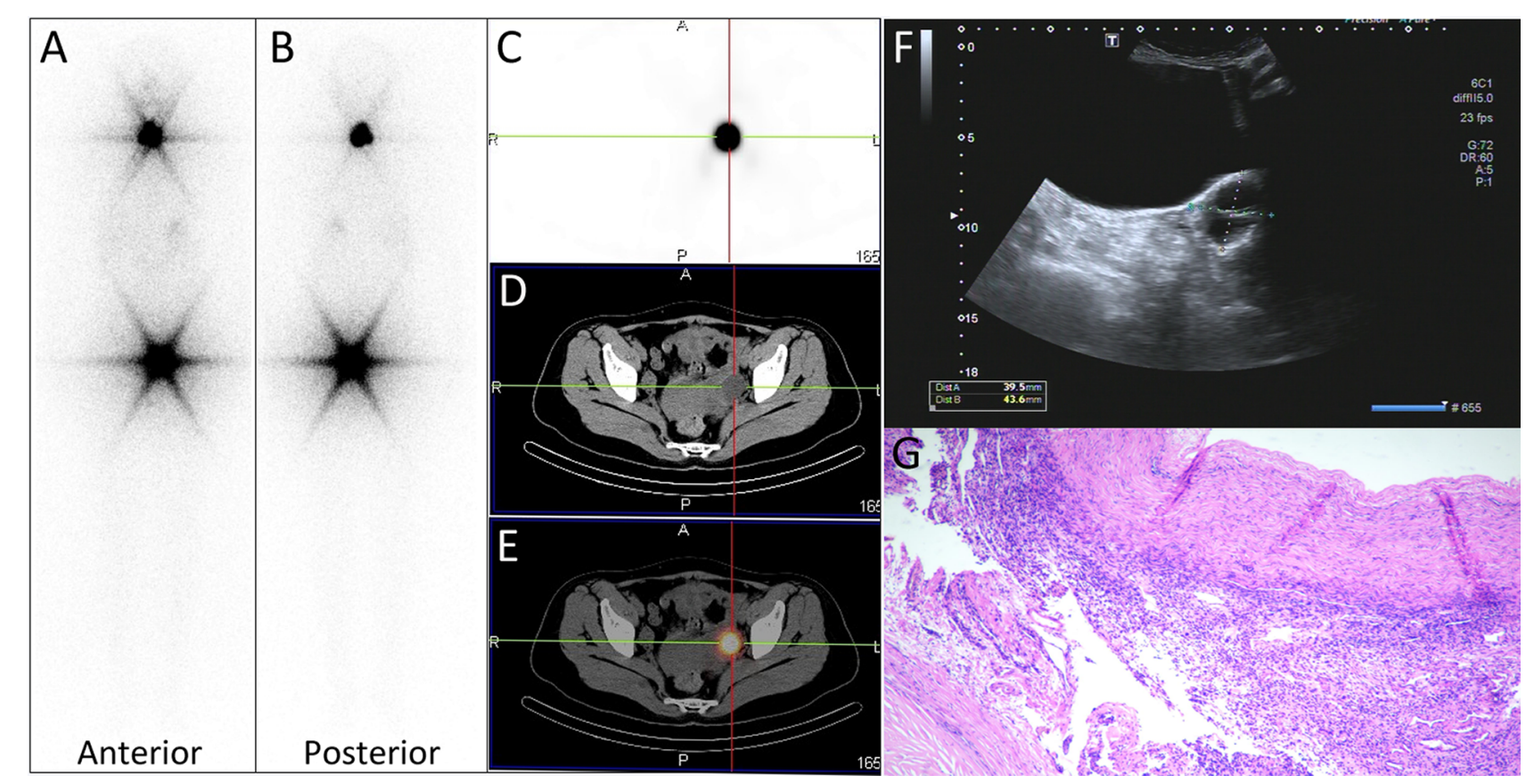

FIGURE 1 | (A, B) panels images showed intense radioiodine uptake in thyroid bed in the neck and unexpected uptake in the left side of the pelvic cavity. (C-E) Axial tomography images demonstrated the unexpected uptake corresponded to a ovarian cyst of approximately $3.2 \times 2.4 \mathrm{~cm}$ in size. (F) The pelvic ultrasonography showed a $4.3 \times 4.0 \mathrm{~cm}$ liquid area with internal separation in the left ovary. (G) Pathologic finding (hematoxylin and eosin staining $\times 40$ ) showed a simple ovarian cyst. 


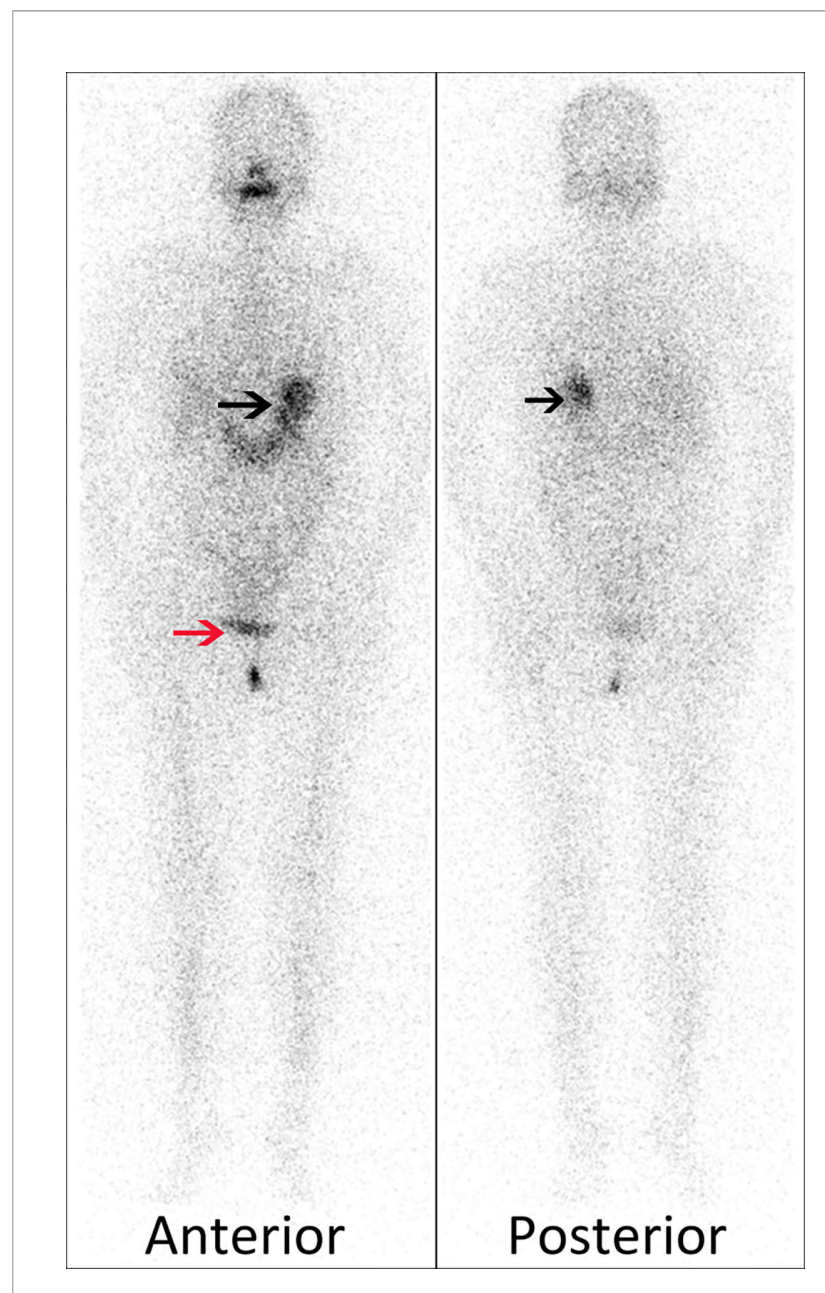

FIGURE 2 | Excepting for the physiological retention of stomach (black arrows) and bladder (red arrow), no radioactive uptake was observed in the neck and pelvic cavity on the diagnostic I-131-WBS.

SPECT is the most commonly used and sensitive diagnostic tool in clinical practice, but its specificity is poor due to the lack of detailed anatomical localization. But SPECT/CT fusion scanning technology can provide more accurate anatomical location (12), which has significantly improved the accuracy of the differential diagnosis of false-positive lesions. A false-positive finding due to a functional ovarian cyst was first described in 2013 (13). But the Tg level of that patient before radioiodine administration was only $43.48 \mathrm{ng} / \mathrm{ml}$, and the ovarian cyst disappeared after 6-month follow-up without any intervention. However, the stimulated $\mathrm{Tg}$ level of this patient in our case was $11,488 \mathrm{ng} / \mathrm{ml}$, and nonstimulated $\mathrm{Tg}$ immediately decreased to $143 \mathrm{ng} / \mathrm{ml}$ after bilateral adnexectomy under laparoscopy three days later and to $0.109 \mathrm{ng} / \mathrm{ml}$ after 4 -month follow-up. Although no mutated epithelial tissue was observed, metastatic cystic lesions cannot be excluded because of such high Tg level. This may be the reason for the rapid decrease of $\mathrm{Tg}$ after resection of the simple cyst, but which is needed to confirm by further immunohistochemistry. Therefore, timely intervention measures are very necessary for patients with ovarian cyst with abnormally elevated $\mathrm{Tg}$ level.
To our knowledge, simple ovarian cyst with such high Tg level has not been previously reported in the literature.

As described in the literature, pelvic false-positive lesions were also reported in struma ovarii (4), serous cystadenoma (14), mucinous cystadenoma (15), granulose cell tumor (16), mature teratoma (17), and cystadenofibroma (18). There are no clear mechanisms for these abnormal uptake except for struma ovarii. Besides, other elsewhere benign cyst can also cause radioiodine uptake, such as hepatic cyst (7), renal cyst (8), nabothian cyst (9), spermatocele (19), thymic cyst (20), dermoid cyst (21), and so on. The possible mechanism for the abnormal uptake in renal cyst is linked to an active secretory process by the renal tubule (22), and in functional cyst is passive diffusion of radioiodine into the cyst (23). However, the exact uptake mechanism still needs further exploration and research.

Although differentiated thyroid cancer is a relatively lowgrade malignant tumor, distant metastases like lung, liver, and bone are also frequently observed in I-131-WBS images. Therefore, how to differentiate and diagnose these falsepositive lesions and prevent these patients from receiving additional internal radiation dose is the focus of clinical practice.

\section{CONCLUSION}

A false-positive case with such high stimulated Tg level results from a simple ovarian cyst has been presented. The nonstimulated Tg immediately decreased to $143 \mathrm{ng} / \mathrm{ml}$ after bilateral adnexectomy three days later and to $0.109 \mathrm{ng} / \mathrm{ml}$ after 4 -month follow-up. So timely intervention measures are very necessary for patients with ovarian cyst with abnormally elevated Tg level.

\section{DATA AVAILABILITY STATEMENT}

The original contributions presented in the study are included in the article/supplementary material. Further inquiries can be directed to the corresponding author.

\section{ETHICS STATEMENT}

The studies involving human participants were reviewed and approved by the ethics committee of the First Affiliated Hospital of Anhui Medical University. The patients/participants provided their written informed consent to participate in this study.

\section{AUTHOR CONTRIBUTIONS}

TW, XZ, and HX performed image acquisition and post-processing and completed the manuscript. All authors contributed to the article and approved the submitted version.

\section{FUNDING}

This work was supported by the National Nature Science Foundation of China (no. 81401448 and no. 81971643). 


\section{REFERENCES}

1. Glazer DI, Brown RKJ, Wong KK, Savas H, Gross MD, Avram AM. SPECT/ CT Evaluation of Unusual Physiologic Radioiodine Biodistributions: Pearls and Pitfalls in Image Interpretation. Radiographics. (2013) 33:397-418. doi: $10.1148 /$ rg.332125051

2. Triggiani V, Giagulli VA, Iovino M, De Pergola G, Licchelli B, Varraso A, et al. False Positive Diagnosis on (131)Iodine Whole-Body Scintigraphy of Differentiated Thyroid Cancers. Endocrine. (2016) 53:626-35. doi: 10.1007/ s12020-015-0750-3

3. Morel O, Rohmer V, Girault S, Muratet JP, Berthelot C, Jallet P. Abnormal iodine-131 Uptake in a Benign Mucinous Ovarian Cystadenoma Mimicking Struma Ovarii. Clin Nucl Med (2007) 32:64-6. doi: 10.1097/ 01.rlu.0000249548.55877.3d

4. Ghander C, Lussato D, Conte Devolx B, Mundler O, Taïeb D. Incidental Diagnosis of Struma Ovarii After Thyroidectomy for Thyroid Cancer: Functional Imaging Studies and Follow-Up. Gynecol Oncol (2006) 102:37880. doi: 10.1016/j.ygyno.2006.01.047

5. Utamakul C, Sritara C, Kositwattanarerk A, Balachandra T. Chotipanich C, Chokesuwattanaskul P. I-131 Uptake in Bilateral Ovarian Endometrial Cysts. Clin Nucl Med (2009) 34:537-8. doi: 10.1097/RLU.0b013e3181abb637

6. Shao FQ, Long Y, Chen XM, Lan XL. Spect/Ct Demonstrating 131i Accumulation in Gallbladder Stone in a Thyroid Cance. Clin Nucl Med (2020) 45:244-5. doi: 10.1097/RLU.0000000000002875

7. Shao FQ. Tang JL, Lan Xl. Variable 131i Activity in Multiple Hepatic Cysts in a Patient With Thyroid Cancer. Clin Nucl Med (2019) 44:324-6. doi: 10.1097/ RLU.0000000000002442

8. Castillo-Berrio C, Zilaya F, Loira F, Castrillón M, López A, Outomuro J. Accumulation of (131)Ina Activity in Renal Cysts Unrelated to Metastatic Disease in a Patient With Differentiated Thyroid Cancer. Rev Esp Med Nucl Imagen Mol (2016) 35:70-1. doi: 10.1016/j.remn.2015.05.010

9. Liu S, Zhang M, Pan Y, Qu Q, Wu HF, Lv J, et al. Nabothian Cyst Associated With High False-Positive Incidence of Iodine-131 Uptake in Whole-Body Scans After Treatment for Differentiated Thyroid Cancer. Nucl Med Commun (2013) 34:1204-7. doi: 10.1097/MNM.0b013e328365911a

10. Tuttle RM, Ahuja S, Avram AM, Bernet VJ, Bourguet P, Daniels GH, et al. Controversies, Consensus, and Collaboration in the Use of 131I Therapy in Differentiated Thyroid Cancer: A Joint Statement From the American Thyroid Association, the European Association of Nuclear Medicine, the Society of Nuclear Medicine and Molecular Imaging, and the European Thyroid Association. Thyroid (2019) 29:461-70. doi: 10.1089/thy.2018.0597

11. Portulano C, Paroder-Belenitsky M, Carrasco N. The Na+/I- Symporter (NIS): Mechanism and Medical Impact. Endocr Rev (2014) 35:106-49. doi: 10.1210/er.2012-1036

12. Campennì A, Vrachimis A, Siracusa M, Baldari S, Giovanella L. Usefulness of 123I-Spect/Ct to Assess the Response to Initial Therapy in Differentiated Thyroid Cancer Patients. Endocrine (2021). doi: 10.1007/s12020-021-02737-7

13. Jang HY, Kim BH, Kim WJ, Jeon YK, Kim SS, Kim KK, et al. False-Positive Radioiodine Uptake in a Functional Ovarian Cyst in a Patient Treated With
Total Thyroidectomy for Papillary Cancer. Intern Med (2013) 52:2321-3. doi: 10.2169/internalmedicine.52.0786

14. Kim EE, Pjura G, Gobuty A, Verani R. 131I Uptake in a Benign Serous Cystadenoma of the Ovary. Eur J Nucl Med (1984) 9:433-5. doi: 10.1007/ BF00295581

15. Morel O, Rohmer V, Girault S, Muratet JP, Berthelot C, Jallet P. Abnormal iodine-131 Uptake in a Benign Mucinous Ovarian Cystadenoma Mimicking Struma Ovarii. Clin Nucl Med (2007) 32:64-6. doi: 10.1097/ 01.rlu.0000249548.55877.3d

16. Kraft O, Mrhac L, Sirucek P, Dvorackova J, Chmelova J, Graf P, et al. I-131 Uptake in an Ovarian Tumor: Differential Diagnosis for Abdominal I-131 Uptake. Clin Nucl Med (2009) 34:390-2. doi: 10.1097/RLU.0b013e3181a344c7

17. Van Wijk JP, Broekhuizen-de Gast HS, Smits AJ, Schipper ME, Zelissen PM. Scintigraphic Detection of Benign Ovarian Teratoma After Total Thyroidectomy and Radioactive Iodine for Differentiated Thyroid Cancer. J Clin Endocrinol Metab (2012) 97:1094-5. doi: 10.1210/jc.2011-2433

18. Flug J, Lameka K, Lee R, Katz DS, Sung WW, Yung E. False-Positive I-131 Uptake by an Ovarian Serous Cystadenofibroma. Clin Nucl Med (2012) 37:178-80. doi: 10.1097/RLU.0b013e31823933d2

19. Albano D, Motta F, Baronchelli C, Lucchini S, Bertagna F. 131i Whole-Body Scan Incidental Uptake Due to Spermatocele. Clin Nucl Med (2017) 42:901-4. doi: 10.1097/RLU.0000000000001838

20. Wilhelm T, Winkens T, Kunze A, Freesmeyer M. 131I and 124I Accumulation in a Thymic Cyst. Clin Nucl Med (2016) 41:972-4. doi: 10.1097/ RLU.0000000000001398

21. Campennì A, Giovinazzo S, Tuccari G, Fogliani S, Ruggeri RM, Baldari S. Abnormal Radioiodine Uptake on Post-Therapy Whole Body Scan and Sodium/Iodine Symporter Expression in a Dermoid Cyst of the Ovary: Report of a Case and Review of the Literature. Arch Endocrinol Metab (2015) 59:351-4. doi: 10.1590/2359-3997000000087

22. Campennì A, Ruggeri RM, Giovinazzo S, Sindoni A, Santoro D, Baldari S. Radioiodine Uptake in a Renal Cyst Mimicking a Metastasis in a Patient Affected by Differentiated Thyroid Cancer: Case Report and Review of the Literature. Ann Nuc Med (2014) 28:472-6. doi: 10.1007/s12149-014-0816-y

23. Shapiro B, Rufini V, Jarwan A, Geatti O, Kearfott KJ, Fig LM, et al. Artifacts, Anatomical and Physiological Variants, and Unrelated Diseases That Might Cause False-Positive Whole-Body 131-I Scans in Patients With Thyroid Cancer. Semin Nucl Med (2000) 30:115-32. doi: 10.1053/nm.2000.5414

Conflict of Interest: The authors declare that the research was conducted in the absence of any commercial or financial relationships that could be construed as a potential conflict of interest.

Copyright (C) $2021 \mathrm{Wu}$, Zhao and Xu. This is an open-access article distributed under the terms of the Creative Commons Attribution License (CC BY). The use, distribution or reproduction in other forums is permitted, provided the original author(s) and the copyright owner(s) are credited and that the original publication in this journal is cited, in accordance with accepted academic practice. No use, distribution or reproduction is permitted which does not comply with these terms. 